zur globalen und intergenerationellen Betrachtung von Landnutzungskonzepten. An diesem Spektrum ist deutlich abzulesen, wie differenziert und vielgestaltig die TA-Landschaft ist.

Sowohl in den Grußworten, als auch in einem Teil der Beiträge wurde deutlich, daß die Thematik dieser Tagung einen wichtigen Beitrag zur nachhaltigen Entwicklung des ländlichen Raumes liefert. Es wird angestrebt. eine Fortsetzung dieser Tagung auch mit internationaler Beteiligung durchzuführen. Der Tagungsband zur Veranstaltung kann unter folgender Adresse bestellt werden: Institut für Agrartechnik Bornim (ATB), Max-Eyth-Allee 100, D14469 Potsdam (Frau Scheidemann: 03315699723 / Fax: -849).

$\gg$

\section{Beyond Sustainability: New Concepts from Amsterdam}

\section{by Krassimira Paskaleva, ITAS}

\section{Perspectives of Conference: Mission and Organization}

From 19 to 21 November 1998 about 160 scientists and policy-makers gathered in Amsterdam, the multicultural capital of the Netherlands, to participate in the international conference Beyond Sustainability: Integrating Behavioral, Economic, and Environmental Research. This multidisciplinary research conference was organized by the Netherlands Organization for Scientific Research (NWO) jointly with the Center of Environmental Science (Leiden University/NL) to conclude a five-year priority research program on 'Sustainability and Environmental Quality' coordinated by NWO. The purpose of the conference was to address the results of this research in the context of similar research programs elsewhere in Europe and around the world aiming to provide an opportunity for discussion and dissemination of the findings to a multi-disciplinary international audience. The foci of the first day, i.e. the main program set up the tone of the meeting.

Following the official opening ceremony, which included welcome and introductory speech by Reinder van Duinen (NWO, The Hague/NL), the bulk of the time during the first day of the conference was given to formally presenting and subsequently reviewing and discussing the three main sub-programs HOME, METALS, and RIVER, supplemented by presentations of their partner programs from Australia, Austria and Sweden, respectively. While the lightmotif, i. e. integrating behavioral, economic, and environmental research", was implicitly touched upon in the RIVER project presented by Eelco Van Beek of Delft University of Linkoping/NL, and also strongly emphasized by Helias Udo de Haes of CML, Leiden University/NL in his presentation of the METAL program, it was explicitly brought up by Tom Uiterkamp of IVEM, University of Gronongen/NL in HOME. In addition, while the overview presentations gave a good insight into the three programs, the partner programs provided additional international context to their framework and outcomes.

This overview was followed by three concurrent sessions during the second day of the conference focusing on: (a) Sustainable household management (b) Flows and accumulations of materials, and (c) Multinational river basin management. The chosen format, allowing the participants enough time after each session of open discussion, was recognized as a major advantage of the conference. A poster session at the end of the first day provided additional insights to the main research themes placing the concepts of sustainable development in various national and regional settings. Main poster topics included household management, land-use modeling of peripheral regions, environmental material flows, and environmental accounting. Consistent with recent foci of research and interests, a considerable attention was given particularly to the consumers' behavior in the context of sustainable consumption, changing life style patterns and the role of various shareholders in the process.

The three comprehensive scenarios of sustainable development presented at the concluding plenary session set up the final scene of the meeting. Three main alternative paths of development were outlined, involving: (a) Weak sustainability, where resources and capital are mutually replaceable with piecemeal environmental problem solving; (b) Maximization of 
eco-efficiency and economic growth by integrated policy; (c) Strong sustainability, comprising the precautionary principle, low substitution of resources and capital, low consumption of resources, lifestyle and technology changes.

In addition to its main goal, as discussed above, the conference also steered towards reaffirming the case of interdisciplinary long-term studies on sustainable development by addressing relevant inadequacies in scientific design, research organization, and funding policies. Accordingly, delegates included both scholars and representatives of funding and regulatory agencies. More than 160 participants from 28 countries from all over the world had the unique opportunity to meet and discuss new theoretical foundations for the design of future policies of sustainable development. Overall, if one were to look for a central theme or a leitmotif inherent in the three main and their partner programs, in around 21 individual paper presentations given in parallel and open discussion sessions, and about 16 oral poster presentations each addressing the conference theme with a broad range of disciplines, it was the notion of a change of paradigm in future research on sustainability.

\section{Conference Highlights: Overview of Essence}

Naturally, the three main topics of the conference composed the core of the program. However, the essence of the agenda was the discussion over the conceptual basis and the guiding view of sustainability - a debate which, in recent years, seems to appeal only to the bold in the field. To no one's surprise, the debate over weak versus strong sustainability, became a major highlight of the conference. The key opponents W. Van Dieren (IMSA/NL) and Eduard J. Bomhoff (Nijenrode University/NL) got into a bitter verbal fight over the key issues 'Which is the right approach to sustainability: The steady-state-technological pessimism or the economic growth-oriented technological optimism?' On one side, Dieren, a world-known advocate of strong sustainability, argued that the latter is the 'only and undisputed answer to the present unsustainable world-course' stating that the 'much praised free market has no in- struments to act against global change and other developments alike', thus 'new environmental ethics is needed to guide individual and collective action and public policy'. On the opposite side, Bomhoff, an established economist, while emphasizing that stocks and flows of natural resources should be included in national accounting as well, he also made the blunt observation that environmentalists are too 'pessimistic about future progress of mankind' and 'do not share any optimism about technological progress' thus obstructing relevant research from successful results. Opportunely, the remarkable mediating talent of the Conference Chair Peter Nijkamp (Free University of Amsterdam) diverted the harsh dispute into a stimulating and enjoyable scholarly discussion.

However, the open question raised by the two scientists was intensively discussed by the audience, overwhelmingly acknowledging that the disputed issue will still remain controversial in the coming years. Yet, it was evident from the expressed opinions, that the idea of strong sustainability is gradually losing some of its advocates while the reasonable center approach is gaining more confidence in both the research and policy community. As Kerry Turner (University of East Anglia) concluded '...the right way to go lies somewhere in-between the two antipodal approaches' arguing that, despite the firm foundations of both perspectives, 'the polar viewpoints lose both natural and social science credibility as soon as the details of the sustainability debate are addressed and practical policy prescriptions are required'. Furthermore, as he indicated, the debate can also be portrayed rather differently, 'once we see the wide spectrum of overlapping sustainability positions in the wide range between very strong, strong, weak, and very weak sustainability'. Therefore, scientists and fields 'must integrate and collaborate in order to better understand and promote the principles of sustainability in life'. Obviously, to accomplish this, a new substantiate multidisciplinary research agenda is needed to straddle a range of disciplines to require a plurality of valuations, waiting to be tackled, and provide findings that could be meaningfully and constructively debated. In this venue, networked disciplinary research teams and findings can apparently lead to significant future interdisciplinary insights. All in all, the confer- 
ence amply demonstrated that the debate is alive, controversial, and enticingly challenging.

\section{The Two Main-Programs ${ }^{1}$}

HOME: The program's main aim was to develop and apply the concepts, operational approaches and instruments relevant for the diagnosis and evaluation of household metabolism in a complex Western society, in the case illustrated by the Netherlands. Since this type of household metabolism is not expected to be sustainable nor qualitatively acceptable, HOME also investigated the changes necessary to household metabolism that does comply with these characteristics. Altogether, it became apparent at the meeting that the issue of resource use by households has attracted a considerable attention in recent studies but it's been mostly European researchers so far who have applied the household metabolism concept to identify pressure points and potentially unsustainable trends in resources usage. In this respect, the HOME project, as pointed out by the reviewers, had accomplished considerable results. In addition, its success was largely due to the integrative approach to the reduction of resources use of households involving the consideration of institutional, economic, and psychological constraints in addition to biophysical impediments.

To summarize briefly, as demonstrated by $H O M E$ and the 6 individual papers in the subprogram, recent household management research has made serious attempts to incorporate the human dimension, focusing on the important role of household values and personal behavior, consumer's role and involvement, and the issue of engaged consumption. Here are some of the main points raised at the conference by both presenters and reviewers:

- Household values and personal behavior are critical elements of sustainable consumption and friendly environmental behavior;

- Quantification of household flows is an important step to evaluating consumers' impacts on the environment;

- Consumers' role should be considered in relationship to the role of producers and distributors;
- Greater involvement of citizen-consumers is needed to actively direct production and marketing policies in utility supply systems and waste services, particularly in urban areas;

- Consumers' involvement should be seen in: (a) normative and functional view, (b) use involvement, and (c) sub-political involvement;

- Success factors of sustainable citizens' consumption need to be identified to assist future policy efforts;

- In domestic consumption of energy and water, consumers should change from captive to authoritative actors;

- Domestic consumption has public underpinning therefore public policies should provide for sustainable household management;

- Political instruments have a great potential to reinforce or improve the lever effect of engaged consumption;

- Eco-team programs can be efficient tools in pursuing sustainable household behavioral changes and perceived behavioral control and habit;

- Green households are promising alternatives to achieve change in consumption patterns of individuals and households. In this regard, the focus should be placed on changing unsustainable patterns of consumer energy uses;

- Both, technological and behavioral changes are required in household energy use to achieve sustainability in household management.

In the policy arena, it was further emphasized that sustainable household management and responsible consumption should become key elements of future sustainable development policies. To achieve sustainable household behavior, adequate implementation settings must be therefore developed. Overall assessment of HOME indicated one of its greatest advantage placing the social science in the lead of household management studies. Most importantly, it was emphasized that the social and the institutional factors convey a tremendous potential for change. Therefore they should be more vigorously examined and seriously considered in future research and policies for sustainable de- 
velopment. In this context, future household management policies should stimulate use of less resourceful incentives including behavior, technologies, and policy simulations. To test results and enhance current approaches, there is obviously a need that similar programs be conducted in other countries and different regional settings.

METAL: The program examined the metal flows in the economy and environment of the Netherlands, looking at cadmium, copper, lead and zinc, in particular. The housing sector and agriculture were in the main focus of the study where major pollution problems were identified. Based on an extensive inventory of metal flows and stocks and the formulation of a comprehensive set of indicators, the project built several types of models, including accounting schemes and balancing procedures, steady state models and dynamic state models, to simulate flows of metals and interactions for several years. The models covered both, the economy (in monetary and physical terms) and environment (analysis of environmental flows). In order to: (a) diminish the complexity of the investigated problems, (b) focus within the program, (c) assure compatibility between the studies, and (d) to translate research findings into policy relevant terms, specific indicators for: (a) fate, (b) risks, and (c) management of metals were formulated as well. The outcomes of the project reflected base indicators: (a) The fate of each targeted metal was defined and its mobility traced, (b) Emissions were compared with existing regulatory standards, (b) Risk ratio was calculated and the levels of toxicity for humans, water and land were calculated. Accordingly, implementation strategies were formulated in three main directions: (a) Lower inflows by increasing life span, recycling, and reduction of trace inflows, (b) Delay of outflows by increasing re-use of materials with traces, and (c) Control of outflows by immobilization of waste primarily.

The foreign partner project Material Flows Through Vienna examined the inflows, stocks, and outflows of water, construction materials, air and energy in the Austrian capital. Using a Material Flow Analysis (MFA), the project developed scenario models for the flow and accumulation of metals in the city. With the help of the model, the impacts of various social and economic developments on the materials management system were forecasted. Hence, the project provided a valuable policy contribution supplying information on possible problem shifts in flows of materials in Vienna thus serving for the long-term planning of the big city. Above all, as implied by the project, it was concluded that, today, in the pursuit of sustainable regional development strategies, the focus should shift from the environment to the more troublesome domain of the anthroposphere. To accomplish the change, decision-makers must become familiar with the idea of urban metabolism. In this, $M F A$ can serve as a powerful management tool to assist actors finding a common policy platform for effective solutions.

Though both reviewers and participants indicated that the program has several important weaknesses, they also acknowledged that METAL has a number of methodological and policy merits which can endure further research in the field. Following is a summary of the main conclusions deriving from the project:

- $\quad M F A$ can be a powerful tool for the analysis of metabolic processes of the regions: It can be used to assess both flows and stocks of materials in the anthroposphere and trace flows and design final sinks for materials;

- $M F A$ has the potential to visualize the complex regional metabolisms, thus allowing objective discussions over environmental and resource policy measures;

- To achieve sustainable regional management of material flows and accumulations both accumulation of goods and substances should be considered;

- To utilize stocks in urban areas appropriate infrastructure needs to be developed;

- New resource utilization strategies are needed to utilize accumulated stocks in urban areas;

- Material stocks should be included and considered in national accounts: A system of materials accounting should be established to supplement the national accounting systems;

- Material Management Offices should replace existing Environmental Protection Departments of city and regional administrations; 
- National, regional, and global measures for resource protection should be integrated based on MFA;

- Compilation of statistical data in the future should be directed towards aiding MFA: A dada base system should be developed to systematize collection and use of data on all levels;

- Substance Flow Analysis, Life Cycle Analysis, and Economic Equilibrium Analysis should be seen as complements (rather than substitutes) to material flow modeling;

- New modes of product use, such as renting or sharing, intensification of use and useful life extension, and a prolongation of the products' useful life (by way of up-grading and repair) appear to be potentially fruitful policy approaches of future product utilization modes.

To summarize, the program was acclaimed for: (a) Setting up normative goals for managing pollution emissions, (b) Building up material flow management models, (c) Accounting for material flows and accumulations within a rigorous scientific framework and a long look into the future, and (d) Offering several practical policy solutions (e.g., Store heavy metals as an alternative to sustainable development as 'closing life cycles is not necessarily the only and single choice in urban material flows management').

However, reviewers and participants raised several critical points deserving a further attention in the field: (a) In addition to accumulation of stocks, MFA should also account for substance mobility and the level of exposure of accumulated substances in terms of impacts on environment, society, human health, and the economy, (b) Harmonized pollutant standards should be used for both air and soils to assess health risks from accumulation of metals, (c) Future Sustainable Material Management (SMM) research should focus on formulating an uniform definition of $S M M$ and developing a system of indicators to assess implementation, (d) Analysis to support $S M M$ should be oriented towards developing strategies for: (i) resource efficiency (factor 4-10), (ii) substitution and control of hazardous materials, (iii) shift towards renewable inputs and, (iv) sufficiency of consumption. Finally, SMM R\&D should extend towards an integrated Sustainable Resource Management (SRM) to go beyond management of material flows and recycling of wastes and consider accumulation of stocks and nature of substances.

\section{Outcomes and Recommendations: What Did We Learn?}

As widely acknowledged by the participants, the Amsterdam conference was a delightful experience for everyone attending the meetings both from a scientific perspective and networking opportunities. The conference posed new challenges to the attendants and inspired many to pursue new directions and ideas in their future research. The lively discussions at the meetings indicated that we can expect an even richer, long term scientific harvest from future research in the field of sustainable development. While specific points relating to the three sub-programs were explored in detail during the three working sessions, a selection of plenary discussion's highlights deserves a special attention.

\section{Organization of Conference}

Most importantly, the conference manifested the significance of undertaking interdisciplinary research in the pursuit of sustainable development. It also confirmed the leading role of the Dutch science and academic community in the field. Furthermore, it demonstrated the strong level of commitment of the Dutch government to promote sustainable development on various levels. Finally, the conference showed the accomplishments of the Dutch society in adopting sustainable behavior and life style patterns in multiple directions. From conceptual framework perspectives, it also became apparent that environmental policies in The Netherlands are gradually shifting from reflecting the egalitarian approach (strong sustainability) to more flexible policies embracing the hierachist perspective (nature is tolerant within limits): Guiding current Dutch policies is the view that economic development can be combined with social responsibility and environmental sustainability. Overall, by building on a far ranging history of previous efforts and activi- 
ties, the conference was a major contribution to the capacity building process in The Netherlands. In this regard, the attention of both the academic and policy-making communities was attracted on the importance of the institutionalization of sustainable development efforts in the future. However, to secure effective implementation, more transparency of information revealed by government agencies to the public will be critically required.

\section{Substance of Conference}

In all, the Amsterdam conference provided a forum to assess the progress of several on-going projects on sustainable household management, sustainable material management, and river basin management, identify emerging problems and exploring solutions for those problems. A critical evaluation of the type of modeling that integrates behavioral, economic and environmental aspects of sustainable development research was also offered. Some key scientific, structural, and organizational problems of the implementation of sustainable development policies were identified. Attempts were made to look into the future and to outline the outlook of research and implementation activities in the next century. Priority research and policy areas were mapped out as well. While almost all discussions were pervaded by lightmotif considerations, an explicit demand was expressed to explore new tools for policy implementation. Central to this would be a reconsideration of the role of the scientists. Active partnerships with private partners and policy makers would be of pivotal importance in the future.

With regard to the integration of human dimensions, it was made clear that research done so far involves more environmental and economic valuation and less cultural, social, psychological and behavioral aspects, and the quality of nature/society relations. While the latter aspects are difficult to assess, they were nevertheless esteemed to be of pivotal importance. In this respect, the conference clearly prioritized the role of the social science in future work on sustainable development. To accomplish this, better methodologies must be developed including some for the extrapolation of human behavior in the future while considering various impact factors. In the same con- text, peoples' intentions, attitudes, habits, behavior control, social norms and personal norms should also be accounted for. To conclude, history, psychology, demography, and cultural sciences should become equally important as environmental sciences, economics, and engineering in research on sustainability. Furthermore, future studies should also deal with the time frame of environmental changes posing the question: Should we care about the impacts and the consequences of our doings now or, in 500 years the new technologies will take care of the problems that present practices create?

Further, it can be pointed out as well, that the conference had several theoretical, conceptual, and methodological accomplishments. To start, it was emphasized that the concept of sustainability, like peace or justice, is so general and fundamental to our humanity that one would have difficulties arguing against it in principle. However, its translation and operationalization into practice has been, so far, rather limited - a fact not cheerful but inspiring. Yet, conference attendees were pleased to learn about new thresholds in the areas discussed. Besides, it was further deliberated that the concept of sustainability can be placed in the context of cultural theory of risk. Thus one can speak of (a) hierarchist (moderate sustainability), (b) egalitarian (strong sustainability), and (c) individual (weak sustainability) perspectives. It was also implied that the use of the sustainability concept depends on the values and beliefs shared within each society which ultimately puts the sustainability problems into the domain of politics. For policy-makers it was reassuring to hear that there are explicit tradeoffs between fairness and efficiency which they should wisely consider in the decision-making processes. To assist the latter, it was underlined that future research priorities should be put on multidisciplinary modeling which should account for material stocks as well. A notion was made also that end-of-the-pipe technologies are still important in pollution prevention practices but way not enough to deal with pollution problems in the long run.

With regard to priorities in research agendas, it was quite clear from what was said that there are still differences in research emphasis between the European, focusing on material flows and stock, and US scholars, emphasizing 
on risk and cost-benefit issues primarily. To enhance compatibility and promote future research, some shifts are obviously needed in the agendas of the two communities.

\section{Implementation and Dissemination: In- sights of use of results by policy-makers}

Though generally not so fruitful on policy prescriptions and implementation techniques, a step ahead was still made in several directions. Major conclusions here include: (a) Quantitative measures are yardsticks in practical solutions, (b) Cost efficiency methods should give way to cost benefit analysis, (c) Eco-efficiency must become a key incentive for future policies, (d) Future research and policy measures should account for the main risks of the well-being of both humans and ecosystems, (d) New framework conditions and more intensive funding are needed for the development of innovative policy approaches. In this, the role of the funder will be decisive.

Among the key issues that were discussed, a special concern was given to the importance of communication and networking between the various actors of sustainable development. It was recognized that the latter is a rapidly growing research field and is remarkably comprehensive, interdisciplinary and still riddled with many unresolved problems. It is not suprising, therefore, that many researchers of all ages are fascinated by it. Nowadays, sustainable development issues are receiving a growing attention even among the general public. Decision-makers and politician rightly ask 'How to achieve the desired goals?' In this respect, the issue of connectivity, efficiency, and (avoidance of) duplication will be central to the success of future research efforts. Having gathered more than 160 scientists from various parts of the world, the Amsterdam conference was clearly very successful in establishing new links between scientists working in interrelated research areas with partly overlapping interests. It provided an excellent opportunity for exchange of information between academics and scientists, policy-makers, and experts about goals, intentions, methods and tools in the target areas.

Despite its numerous merits, the Amsterdam conference had few significant weaknesses, among which the most important was the lack of working policy measures to assist implementation efforts in the discussed fields. Also, little was done to link problems and solutions to respective institutions and players. Behavioral patterns and practices were mostly examined at the individual level failing to look at the entire social system with its complex structure. Overall, the presenters provided limited policy analysis and implementation instruments. The prescribed policy interventions were general and sometimes vague. Further, the organizers of the conference were criticized for failing to provide the audience with information on similar projects elsewhere. Printed papers and other hand out materials were also scanty.

\section{Major Recommendations, deriving from the Conference: What will the conference in- spire for?}

The conference ended with a discussion of what has been overlooked to date and what should be done to overcome deficits in current research and policy efforts in the discussed areas. It was emphasized that theory-oriented experimentation should give way to policy-oriented research. To assist this, a new theory-based policy framework should be developed. Future policy research should include participative design of policy scenarios considering development trends, time-scales, and temporal discounting of study factors. Ultimately, the policy models should be simple to allow successful implementation. Overall, it was made explicit that research programs should be viewed as interventions in society's innovation capacity. Multidisciplinary approaches have to become leading in dealing with the complex issues of sustainable development. In addition, the conference also called for involving multidisciplinary training in academic institutions. At the end, summarizing the general baseline of the conference, the chair closed the plenary session by stating that multidisciplinary policy-oriented research programs require substantial amount of time, efforts, and money, therefore, joint efforts are essential for their success.

\section{Conclusion}

Sustainable development research has achieved a great and visible progress in recent years. It is, 
of course, still developing innovative approaches but it should be emphasized that our knowledge of the interactions between all systems is yet limited and calls for future efforts in both research and allocation of funding. The transition to sustainability during the last decade has been beset by a clash of interpretations and reactions regarding the essence, the purpose and the path to sustainable development. The intensification of the process of global environmental change and its manifestation across a range of temporal and spatial scales has served to highlight the importance of the contemporary sustainability debate. But while sustainable development has been accepted as a general policy goal, a practicable implementation strategy has yet to be devised. Decision-makers, who have a growing demand for a better scientific foundation of their decisions, as well as the general public are seeking for an efficient "toolbox" which scientists are expected to provide. For sustainability needs to be delivered and the process will require mechanisms for delivery of change, as Kerry Turner pointed out. As there are still major deficits in our knowledge of these mechanisms. Therefore, a conference devoted to the applications of sustainability implementation methods is very important at the interface of all communities involved. Furthermore, holding it in a specific regional framework will be sensible as the shift in sustainable development is towards regional perspectives to maintain and strengthen the network of application- oriented scientific activities. As it must be admitted that we are only at the very beginning of making sustainability real. To bring integrated environmental concerns into all aspects of social and economic life brings unprecedented cultural and political challenges. Apparently, the causes of unsustainable human activities lie in current lifestyle choices, patterns of consumption, and production activities. The new direction should be the one of shifting perceptions of environmental risk, changes in demography and household formation, cultural pluralism and changing relationships between individuals and governance institutions in all levels.

Will the insights of the conference endure? The turn of the century represents the deadline for many projects aimed at achieving sustainable development outcomes. The new century will bring with it a new sense of environmental urgency. Perhaps, the people who attended the Amsterdam conference were those who were willing to meet those challenges.

\section{Note:}

1 The author of this report will focus only on the HOME and METAL programs as per her personal research interests and professional experience.

$\ll$

\section{"Geistiges Eigentum und Copy- right im multimedialen Zeitalter - Positionen, Probleme, Per- spektiven. Eine fachübergrei- fende Bestandsaufnahme}

Unter diesem Titel wurden die Beiträge eines gleichlautenden Fachgesprächs in dem Band Nr. 13 der Grauen Reihe zusammengefaßt, der auf Anfrage kostenlos bei der Europäischen Akademie $\mathrm{GmbH}$ bezogen werden kann.

Zum Thema "Geistiges Eigentum und Copyright im multimedialem Zeitalter - Positionen, Probleme, Perspektiven." fand am 12. März 1998 in Bonn ein Fachgespräch der Europäischen Akademie statt, an dem rund 30 Fachleute aus Wirtschaft, Politik und Wissenschaft teilnahmen. Nach einer thematischen Einführung von Dr. Christian J. Langenbach (Europäische Akademie) wurde unter der Moderation von Dr. Armin Grunwald (Europäische Akademie) und Dr. Otto Ulrich (Bundesamt für Sicherheit in der Informationstechnik, Bonn) in den Referaten der (inter-)nationale Diskussionsstand aus verschiedenen Blickwinkeln erfaßt und zwar hinsichtlich erreichter Positionen und offener (Forschungs-)Fragen ("Probleme"). Die sehr lebhaft geführten Diskussionen hatten vorrangig die Suche nach vorhandenen oder möglichen Lösungsrichtungen ("Perspektiven") der dargestellten Themen zum Gegenstand. Zum Abschluß des Fachgespräches unternahm Professor Dr. Gerhard Banse (Brandenburgische Technische Universität Cottbus / Europäische Akademie) den Versuch einer themenorientierten "Bündelung" des dargelegten Wissens aus der Sicht der Technikfolgenbeurteilung. 